\title{
Erratum to: Poor institutions as a comparative advantage
}

\author{
Cortney Stephen Rodet ${ }^{1}$
}

Published online: 31 October 2016

(C) Springer Science+Business Media New York 2016

\section{Erratum to: Const Polit Econ \\ DOI 10.1007/s10602-016-9224-8}

In the original publication of the article, there is an error in Sect. 2.1. The model in the paper includes a probability of successfully avoiding interdiction when supplying illicit goods. In one paragraph, the article mistakenly refers to the probability of failing to avoid interdiction and includes the incorrect sign when comparing the quality of institutions between the two countries in the model, North and South. The reference should be to the probability of successfully avoiding interdiction. The following text corrects the mistake:

When considering the supply side of the model, I impose the restriction that illicit goods are produced using a Leontief technology, $q_{z}=\min (q(1), \ldots, q(z))$, where $z$ represents the number of stages required to get the illicit good to market. Labor, $L$, is the only factor of production hired in the intermediate good sectors. For each intermediate step, there is an independent probability of success of avoiding detection, where the overall probability of successful subversion is expressed as $\rho(z)$. This means the output of a particular illicit commodity is $\min (l(1), \ldots, l(z))$ with probability $\rho(z)$ and zero with probability $1-\rho(z)$. As the complexity of production is rooted in the number of intermediate steps required in trade, a higher $z$ means a greater number of opportunities for something to go wrong (i.e., $d \rho / d z<0)$.

The online version of the original article can be found under doi:10.1007/s10602-016-9224-8.

Cortney Stephen Rodet

rodet@ohio.edu

1 Department of Economics, Ohio University, Athens, OH 45701, USA 
Suppose North and South differ in their institutional quality (enforcement of the rule of law). This is indicated by $\rho_{N}(z)<\rho_{S}(z)$ for any $z$, meaning North is relatively better at enforcing prohibition.

Based on the production technology, there are $z$ intermediate steps in production and a probability of successful subversion equal to $\rho(z)$, implying that the expected output per worker is given by $\frac{\rho(z)}{z}$ in that industry. This implies that $a^{N}(z)=\frac{z}{\rho_{N}(z)}$ and $a^{S}(z)=\frac{z}{\rho_{S}(z)}$, which indicate that a higher institutional quality implies a greater unit labor requirement in illicit markets. This provides the result that comparative advantage will be divided along the continuum of goods according to unit labor costs, as indicated in the original article.

Finally, in Sect. 2.3, the possibility of corruption would allow South to expand its production of illicit goods through the increase of $\rho_{S}(z)$ rather than decreasing it. 